\title{
Delinquent Behavior of Dutch Rural Adolescents
}

\author{
Don Weenink
}

Received: 19 July 2010/ Accepted: 7 March 2011/Published online: 23 March 2011

(C) The Author(s) 2011. This article is published with open access at Springerlink.com

\begin{abstract}
This article compares Dutch rural and non-rural adolescents' delinquent behavior and examines two social correlates of rural delinquency: communal social control and traditional rural culture. The analyses are based on cross-sectional data, containing 3,797 participants aged 13-18 (48.7\% females). The analyses show that rural adolescents are only slightly less likely to engage in delinquent behavior. Furthermore, while rural adolescents are exposed more often to communal social control, this does not substantially reduce the likelihood that they engage in delinquent behavior. Concerning rural culture, marked differences appeared between rural and non-rural adolescents. First, alcohol use and the frequency of visiting pubs were more related to rural adolescents' engagement in delinquent behavior. Second, the gender gap in delinquency is larger among rural adolescents: whereas rural boys did not differ significantly from non-rural boys, rural girls were significantly less likely to engage in delinquent behavior than non-rural girls. However, the magnitude of the effects of most indicators was rather low. To better account for the variety of rural spaces and cultures, it is recommended that future research into antisocial and criminal behavior of rural adolescents should adopt alternative measurements of rurality, instead of using an indicator of population density only.
\end{abstract}

Keywords Rural adolescents - Juvenile delinquency . Rural sociology $\cdot$ Rural crime

\footnotetext{
D. Weenink $(\bowtie)$

Department of Social Science, Rural Sociology Group,

Wageningen University, Hollandseweg 1, P.O. Box 8130,

$6706 \mathrm{KN}$ Wageningen, The Netherlands

e-mail: Don.weenink@wur.nl
}

\section{Introduction}

In many industrialized societies, life in the countryside often is perceived as pleasant and trouble free, whereas life in the city is regarded as dangerous and crime ridden (Van Dam et al. 2002; Frank 2003; Short 2006). While the ideology of the idyllic rural may want us to believe that crime rates are lower or even nearly absent in rural areas, we should not take this for granted. Furthermore, the idea that weakened social controls and anonymity result in higher crime rates in big cities primarily has been "an article of faith in much criminological and social scientific inquiry since the nineteenth century" (Carrington and Scott 2008, p. 644). This article contributes to a more balanced view by evaluating the rural idyll through comparative analyses of rural adolescents' delinquent behavior in the Netherlands. The analyses are based on self report data, consisting of a representative national sample of 3,797 participants aged 13-18. Data were collected by Statistics Netherlands in a cross sectional design.

This article seeks to address two questions. The first question involves the extent to which rural adolescents' rates of delinquent behavior differ from those of adolescents living in more urbanized parts of the country. The second question centers on the extent to which the social correlates of delinquent behavior differ between rural adolescents and their counterparts living in more urbanized parts of the country. The research is framed from two perspectives. The first one follows the social disorganization approach in criminology, which seeks to explain differences in crime and deviant behavior in differing degrees of informal social control. From the second perspective, cultural differences between rural and more urbanized areas are thought to account for differences in juvenile delinquent behavior. We have derived five hypotheses from 
these two approaches. Testing these hypotheses offers an assessment of the two approaches' ability to account for rural adolescents' delinquency rates.

It should be noted here that the Netherlands are a small and overall rather strongly urbanized country, as compared to other industrialized countries. Despite marked social and cultural differences between rural and urban dwellers (see below), the Dutch countryside has nothing of the remoteness of some of the rural areas in neighboring countries and in the US. And even in the least populated areas, the nearby town is within reach of an hour's drive by car. This probably means that if we are to find differences between Dutch rural adolescents and adolescents living in more urbanized areas, they are at least as likely to appear in countries where the remoteness of rural areas is more outspoken-assuming that a greater degree of remoteness also results in greater social and cultural rural-urban distinctions.

\section{Prior Research on Rural-Urban Differences} in Delinquent Behavior

Earlier studies by Laub (1983) and Weisheit and Donnermeier (2000) found that crime and delinquency rates are higher in more densely populated areas (but see Bao et al. 2004 who find higher delinquency rates among Chinese rural juveniles, after controlling for negative emotions). Recent research by Harden et al. (2009) found that youth living in areas of greater population density exhibited more self-reported antisocial behavior across 10-17 years as well. However, their longitudinal analyses revealed that when people move to more densely populated areas, their likelihood of engaging in delinquent behavior does not increase. They thus conclude that it is not population density per se that accounts for higher rates of delinquency in urban areas. Here we focus the analysis on social and cultural aspects of rural life that are thought to be related with juvenile delinquency.

Rural sociologists (Cloke 2006; Halfacree 1993; Murdoch et al. 2003) sensibly have argued that there is not just one countryside and that the rural-urban dichotomy hides important differences between rural places from view. In this article, the focus is on comparing two rural areas (the so called non-urbanized and sparsely urbanized areas) with the rest of the country, to reveal the particularities of rural delinquency, rather than defining the rural as the positive opposite of the urban. We will distinguish these rural areas on the basis of population density (through a measure of "urbanization", see below). One reason to do so is that comparative analyses of the social relationships of Dutch rural and urban dwellers use the same measure. This article is a first step in the analysis of rural adolescents' delinquent behavior in Europe, subsequent work should develop more fine-grained analyses between rural areas, for example on neighborhood level.

\section{Two Perspectives on Rural Adolescents' Delinquent} Behavior

As indicated, we will relate two perspectives to rural adolescents' delinquent behavior. The first one comes from social disorganization theory in criminology, which explains differences in delinquency by varying degrees of informal social control. The second one focuses on cultural differences between rural and more urbanized areas in explaining delinquency rates. We restrict the analyses to property offenses and violence. These forms of delinquency should be distinguished from other forms of delinquent behavior which do not necessarily have direct negative consequences for others, like underage drinking (below the age of 16 in the Netherlands), possessing more than the tolerated amounts (five grams) of soft drugs (cannabis), using hard drugs or playing truant. As these forms of delinquency are also related to both property offenses and violence, we will refer to them as risk behavior.

\section{Informal Social Control}

The idea that informal social control reduces crime forms the cornerstone of a great tradition in criminological research (Bursik 1988; Sampson 2009; Sampson and Groves 1989; Sampson and Raudenbush 1999). A classic work is Shaw and McKay's (1942) book on juvenile delinquency in Chicago. Their observations on rapidly changing urban neighborhoods and poverty are still important features of what is now recognized as social disorganization theory. The core idea is that the combined effects of economic disadvantage, ethnic heterogeneity, residential mobility and single parent families decrease a community's ability to exert informal social control over public space, which eventually may result in rising crime rates. For example, Sampson and Groves (1989) found that the presence of unsupervised adolescent peer groups on the streets was a strong predictor of violent behavior among this age group.

Although social disorganization theory seems skewed towards impoverished inner-city neighborhoods, studies that analyze the prevalence of (violent) crime in US rural areas are inspired by this perspective as well (Barnett and Mencken 2002; Bouffard and Muftic 2006). A consistent finding of this research is that increasing residential instability and higher rates of single parent families in rural areas are, like in inner city neighborhoods, related to rising levels of crime. Thus, the proposed mechanism that 
informal social control lessens crime should also be valid for inhabitants of rural areas.

Most studies in this approach do not observe the practice of social control directly (except for Sampson and Raudenbush 1999), but analyze proxies for collective efficacy - a community's ability to maintain order in public spaces-like aggregated participation rates in community organizations and local activities, mutual trust, knowing one's neighbors and shared expectations of control over the area. There are several indications that exposure to communal social control is likely to be greater in Dutch rural areas as compared to more urbanized areas. First, people living in rural areas are more oriented to their local social network. For example, they not only have more contacts with neighbors but also have a larger chance to meet acquaintances or friends at school, on the street, in the café, at the sports club or in the church (Devilee and De Hart 2006; Simon et al. 2007). In addition, rural dwellers more often are members of local associations and clubs and the proportion of religious adherents and the frequency of churchgoing is clearly higher among inhabitants of rural places (Vermeij and Mollenhorst 2008). Village dwellers themselves think that communal social control remains a distinctive characteristic of village life (Simon et al. 2007). Finally, rural communities tend to have a more homogenous population in terms of ethnicity, and a more stable population concerning residential mobility (Steenbekkers et al. 2006). According to the social disorganization approach, all these features enhance collective efficacy and should thus result in lower delinquency rates.

Rather than analyzing (proxies for) rural and urban communities' ability to accomplish informal social control, we analyze the impact of juveniles' exposure to situations of communal social control. The proposed causal mechanism remains the same, but the units of analysis are individuals, rather than communities. In line with this focus, Mahoney (2000; Mahoney and Stattin 2000) found that adolescents who are active in associations are less likely to engage in antisocial behavior. We will consider three types of communal social control: participation in associations, and clubs, religious affiliation and church attendance. Given the results of research into rural social relationships, we expect that youngsters who live in the former areas are more often exposed to communal social control, and therefore engage less likely in delinquent activities.

Another important criminological tradition focuses on the influence of (deviant) peer groups to explain juvenile delinquency. One perspective within this tradition emphasizes the effects of selection: delinquent youth tend to seek similarly delinquent youth (Hirschi 1969). Other authors working in this tradition emphasize that delinquency is learned in a group of peers (Sutherland et al. 1992). Furthermore, the intensity of the relationships with (delinquent) peers (frequency of meeting, attachment, degree of peer pressure) are seen as affecting the likelihood of engaging in delinquent behavior (Agnew 1991; Haynie and Osgood 2005). Currently, both selection, learning and intensity of the relationships are seen as mutually reinforcing processes that contribute to deviance and delinquency (Aseltine 1995; Matsueda and Anderson 1998). Whereas most studies analyze whether participants have delinquent peers, one Dutch study found that the frequency of meeting peers as such, regardless of their delinquent activities, even results in a greater likelihood of engaging in delinquent behavior (van de Rakt et al. 2005). Here, we will assess the influence of peers by observing the frequency of meeting friends and by analyzing risk behavior that mostly takes places in groups of peers (drinking alcohol, using drugs, truancy and visits to cafés). We expect that the impact of peers and risk behavior on the likelihood of committing delinquent acts is mitigated through communal social control among rural adolescents in particular.

\section{Cultural Differences}

The rural Dutch, both men and women, are markedly more traditional concerning gender roles than inhabitants of cities (see Adolfsen et al. 2006; Bock 2004). To be more precise, rural dwellers are more likely to uphold a clear distinction between men's and women's activities, also with regard to their presence in public space (male dominated) and domestic space (female dominated). As most forms of delinquent behavior are staged predominantly in public space, it is plausible to expect that there is a larger gender gap in delinquent behavior among rural juveniles. The more traditional value orientations also are expressed in the lower divorce rates among rural dwellers (Steenbekkers et al. 2006). Many criminological studies have observed that juvenile delinquency is related to parental divorce. One proposed causal mechanism is that single parents have less time to supervise their children, which consequently results in an increased chance to engage in (violent) crime and deviant behavior (Loeber et al. 2005; Sampson and Laub 1992). Another approach views parental divorce as causing strain and negative emotions, which results in an increased likelihood to engage in delinquency (Agnew and White 1992; Hay 2003). Whatever the causal relationship between parental divorce and juvenile delinquency, we expect that the rates of delinquent behavior of rural youth are lower because of the lower rates of parental divorce among rural dwellers.

Yet another form of traditional culture was observed by Campbell (2000, p. 571) who analyzed the performance of rural masculinity in New Zealand pub drinking. He argues that a successful performance of "pub(lic) masculinity" requires "drinking fitness": the "consumption of large 
quantities of beer and yet maintaining the appearance of total sobriety and self-control" in the local pub. Now it seems that beer drinking is a pivotal element of Dutch rural youth subculture. Drinking takes place in the weekend, often in self-made "booze shacks", specifically designed for collective beer drinking among rural, predominantly male, youngsters. A Dutch study reports that one of the motives for visiting such shacks is the opportunity to drink large quantities of alcohol with friends (Mulder 2005). Let us assume that achieving "drinking fitness" is a common form of embodied masculinity among these rural boys as well (see Tomsen 1997 on the relationship between masculinity, alcohol and violent crime). Criminological studies report an association between alcohol and delinquency and norm-breaking behavior, although the causal mechanism is disputed (Raistrick et al. 1999). Assuming that rural young males drink larger quantities of alcohol and more often visit pubs, we expect that these forms of risk behavior are related to rural youth delinquency in particular.

\section{Hypotheses}

We now derive hypotheses to test the two theoretical accounts of delinquent behavior of rural adolescents. The first two hypotheses depart from social disorganization theory and its application to the analysis of rural delinquency. Hypothesis 1 states that rural adolescents' greater exposure to communal social control substantially reduces the likelihood that they engage in delinquent behavior, as compared to non-rural adolescents. As the emphasis is on the assumed mitigating effect of communal forms of social control, this hypothesis also puts common sense notions of the idyllic rural to the test. Hypothesis 2 posits that rural adolescents' greater exposure to communal social control substantially mitigates the association between peer-related risk behavior and the likelihood that they engage in delinquent behavior as compared to non-rural adolescents. This latter hypothesis combines social disorganization theory with criminological approaches that regard delinquency as a result of adolescents' learning from and selection of deviant peers.

In addition to the two hypotheses mentioned above, we formulated three hypotheses to test the extent to which traditional rural culture may account for juvenile delinquent behavior. One such feature of traditional rural culture concerns the more strict division of gender roles and their different positions in public and domestic space. Reasoning from this perspective, young rural females in particular should engage less often in delinquent behavior. The resulting gender gap in delinquent behavior may even account for the overall difference in delinquency rates between rural adolescents and adolescents living in more urbanized parts of the country. Hypothesis 3 states that the difference in delinquency rates between rural and non-rural girls on the one hand is substantially larger than the difference in delinquency rates between rural and non-rural boys on the other hand. Another cultural difference that may account for differences in delinquent behavior concerns drinking alcohol and pub visits as part of traditional rural masculinity. Thus, hypothesis 4 claims that drinking alcohol has a stronger effect on young rural males' delinquent behavior as compared to young non-rural males because the former drink larger quantities of alcohol and go to pubs more often. Finally, the more traditional value orientations of rural dwellers also appear in their lower rates of parental divorce, which has proved to be a predictor of delinquency. Hypothesis 5 posits that the lower divorce rates among parents of rural adolescents substantially reduce the likelihood that they engage in delinquent behavior, as compared to non-rural adolescents. In the following section, we describe the data to test these hypotheses.

\section{Method}

\section{Sample}

The dataset is part of a national representative sample of Dutch people aged 12-30, collected by Statistics Netherlands. This cross-sectional survey is part of the so-called "Permant Research on Living Conditions" [Permant Onderzoek Leefsituatie]. The data were collected by means of a computer aided personal interviewing questionnaire. In 1997, 2001 and 2003 this survey contained a specific module to gain insight into the lives of youngsters and young adults, including a series of questions concerning delinquent behavior. We combined these three waves and removed all cases in which age was under 13 and those in which age was of over 19. The resulting dataset contains information on 3,797 youngsters. Subsequently, we linked this database to another one, also provided by Statistics Netherlands, which contained the degree of urbanization of the area in which each participant lived at the time of data collection. The data lacks more detailed information on place of residence, so that we cannot group participants into a neighborhood level in order to perform multi-level analyses.

Note that the analyses to follow cannot tell where the actual delinquent behavior took place; we only can relate the place of living to delinquency rates. However, most Dutch youth spend their time, leisure time in particular, in the close environment of the place they live in. And even though rural youth tend to travel longer distances to go out as compared to urban youth, they often travel to places where they meet other rural youth of the region (Emmelkamp 2004). 
Indicators

\section{Delinquent Behavior}

We constructed a scale of delinquent behavior, consisting of items which combine property offenses and violence: "Did you ever use graffiti"; "Did you ever set fire to something illegally?"; "Did you ever damage something which was not yours on purpose", "Did you ever steal something at school"; "Did you ever steal something from a shop"; "Did you ever steal something at work"; "Did you ever steal a bicycle?"; "Did you ever sell a stolen good"; "Did you ever threaten someone"; "Did you ever take part in a fight?"; "Did you ever hit someone badly enough to need medical care from a doctor or nurse?"; "Did you ever carry a weapon" and "Did you ever wound someone with a weapon?". The answers on these questions could be no $(=0)$ or yes $(=1)$. Missing cases were excluded. The scale was constructed by counting the number of positive answers. Cronbach's alpha of this scale is 0.769 . The data set we rely on does not include more detailed measurements, like items that capture the frequency of certain behavior in a period of time. Here, the interest lies in the proportion of youth who engage in delinquent behavior rather than the frequency they do so.

\section{Urbanization}

To distinguish rural regions, we included the Statistics Netherlands' measure of urbanization (Den Dulk et al. 1992), which is actually a measure of address density. The same indicator also was used to distinguish rural from urban areas in the studies on Dutch rural-urban differences mentioned above. This scale of urbanization defines five types of areas: non-urbanized areas: less than 500 addresses per square kilometer, sparsely urbanized areas: $500-1,000$ addresses, moderately urbanized areas: 1,000-1,500 addresses, strongly urbanized areas: 1,500-2,500 addresses and very strongly urbanized areas: more than 2,500 addresses. We took the first and second category (nonurbanized and sparsely urbanized) as indicators for two rural areas respectively and combined the others into one rest of the country reference category. To determine whether the findings were robust, we conducted additional analyses in which we used the original five items ordinal scale of urbanization, rather than dummy variables.

\section{Weekly Participation in Activities of Associations or Clubs}

A binary "Do you participate in activities of clubs or associations once a week?" (no $=0$; yes $=1$ ).
Religious Affiliation

In social disorganization and social bonds theory (Hirschi 1969), adhering to a religion is seen as a tie to conventional society, which prevents people from committing delinquent acts. The survey question is whether the participant feels he or she belongs to a religion $($ no $=0$; yes $=1)$.

\section{Frequency of Attending a Religious Meeting}

The frequency of visits to religious meetings is observed as follows: $1=$ does not attend religious meetings; $2=$ less than once a month; $3=$ once a month; $4=$ twice or three times a month; $5=$ once a week or more.

\section{Frequency of Meeting Friends}

The frequency of meeting friends is observed through the following scale: $1=$ seldom; 2 = less than once a month; $3=$ once a month; $4=$ twice or three times a month; $5=$ once a week or more.

\section{Number of Alcoholic Drinks in the Weekend}

Most drinking among youth occurs in the weekends, so we included the self reported number of glasses of alcohol consumed in the weekend, ranging from 0 to 80 and more. We had analyzed other measurements of drinking behavior as well (frequency of drinking whole week, number of alcoholic drinks on weekdays), but the predictive values of these indicators were clearly lower. It should be noted that drinking alcohol is very common among Dutch juveniles. Youngsters are allowed to buy alcohol at age 16, but underage drinking is generally tolerated. In fact, nearly half of the Dutch adolescents had already drank alcohol at age 12 or lower (Koning et al. 2010; Poelen et al. 2005).

\section{Visits to the Pub}

The frequency of visiting the pub is measured as follows: $1=$ seldom; $2=$ less than once a month; $3=$ once a month; $4=$ twice or three times a month; $5=$ once a week or more.

\section{Drugs Intake}

We composed a scale of the following binary items concerning the consumption of drugs: "Did you ever used...": "hash"; "heroin"; "XTC"; "cocaine"; "amphetamines"; "mushrooms". The answers on these items could be no $(=0)$ or yes $(=1)$. The resulting scale runs from 0 to 6 . Missing cases were excluded, Cronbach's alpha is 0.75 . 


\section{Truancy}

This is a binary, related to the question whether the participant had played truant the past 2 months $1=$ yes; $0=$ no.

\section{Gender}

Males were coded 1 , females 0 .

\section{Educational Level}

Dutch children are assigned to different levels of secondary education on the basis of a national test [cito] that takes place in the final year of primary school as well as on the "school-recommendation" that is given by their primary school. This recommendation attempts to evaluate the ability of the child in the broader perspective of its overall achievements at primary school. Test scores and recommendations determine the level of secondary education that children will be attending in their teens, and only a small proportion of pupils are able to climb their way up through the different levels of the system at a later age. These levels consist of 4-year vocational programmes and 5 to 6-year "general" secondary education. The educational level of participants was captured by the type of education they attended at the time of data collection, or, in case they already completed education, the highest educational level they had attained. This resulted in the following scale: $1=$ primary education (participants over age 12 who were attending primary education or who had dropped out of education at the time of data collection); $2=$ lower secondary education (vocational programmes and the first 3 years of general education programmes); $3=$ higher secondary education (the higher classes of general education programmes) and $4=$ higher education.

Age

This is the age of the participant in years.

\section{Ethnic Minority}

Unfortunately, the dataset lacks a proper measurement of ethnicity. We have to do with the question whether the participant is of Dutch nationality $(=0)$ or not $(=1)$. As most ethnic minorities have the Dutch nationality, this indicator is a crude proxy for ethnic descent. Therefore, we added all participants who indicated they were adherents of Islam, assuming that most of them belong to the Turkish and Moroccan ethnic minority. So, we cannot distinguish the other two large ethnic minority groups in the Netherlands, the Surinamese and the Antillean.

\section{Divorced Parents}

This is a binary, which indicates whether the parents of the participant are divorced (no $=0$; yes $=1$ ).

Analytical Procedure

First, we compared the scores on all indicators between adolescents living in non-urbanized and sparsely urbanized areas and youth living in the rest of the country. In the case of indicators at ordinal or interval level, we used analyses of variances, Bonferroni post-hoc tests to compare mean scores. In the case of binaries, we used chi-square tests to determine significant differences. The results of these analyses are presented in Table 1 and discussed in the next section.

Second, we transformed the delinquent behavior measure. As 37.7 percent of all participants indicated that they had not engaged in any of these forms of action, the distribution of the data is skewed towards zero. Inspection of Q-Q plots indicated that square root transformation comes closest to the normal distribution. Therefore, we used the transformed variable in the regression analyses. Potential error that may result from violating the normality assumption is further reduced by using binary variables.

Third, we used ordinary least squares regression analyses to test the hypotheses. The analyses consisted of separate models in order to test hypotheses. The first model only includes year of data collection and dummy variables, with the adolescents living in the rest of the country as a reference category. Subsequent modeling included the predictor variables step by step. The results are presented in Table 2.

Finally, we ran the analyses again. In a first round, we added a dummy variable, comprising of the most densely populated areas (very strongly urbanized areas, see above) to see whether big city adolescents differ from their rural counterparts specifically. In a second round, we replaced the dummy variables by the ordinal measure, containing five levels of urbanization. The results of these analyses are summarized in Table 3.

\section{Results}

\section{Descriptive Statistics}

In this section, we will compare adolescents living in nonurbanized, sparsely urbanized areas and the rest of the country, based on the results shown in Table 1, which provides average scores and percentages for all indicators, by the area in which adolescents live.

Concerning delinquent behavior, adolescents living in sparsely urbanized areas engage in slightly less frequent 
Table 1 Characteristics of two categories of rural adolescents and adolescents living in the rest of the country

\begin{tabular}{|c|c|c|c|c|c|c|c|c|c|c|}
\hline \multirow[t]{2}{*}{ Measure } & \multirow[t]{2}{*}{ Min-max } & \multicolumn{2}{|c|}{$\begin{array}{l}\text { Non- } \\
\text { urbanized }=1\end{array}$} & \multicolumn{2}{|c|}{$\begin{array}{l}\text { Sparsely } \\
\text { urbanized }=2\end{array}$} & \multicolumn{2}{|c|}{$\begin{array}{l}\text { Rest of the } \\
\text { country }=3\end{array}$} & \multirow{2}{*}{$\begin{array}{l}1 \text { versus } 3 \\
p\end{array}$} & \multirow{2}{*}{$\begin{array}{l}2 \text { versus } 3 \\
p\end{array}$} & \multirow{2}{*}{$\begin{array}{l}1 \text { versus } 2 \\
p\end{array}$} \\
\hline & & $\mathrm{M} / \%$ & $\mathrm{SD}$ & $\mathrm{M} / \%$ & SD & $\mathrm{M} / \%$ & SD & & & \\
\hline Delinquent behavior & $0-13$ & 1.762 & 2.294 & 1.635 & 2.196 & 1.921 & 2.294 & n.s. & .003 & n.s. \\
\hline Weekly visits clubs/associations & $0-1$ & $67.8 \%$ & & $66.4 \%$ & & $57.9 \%$ & & 0.000 & 0.000 & n.s. \\
\hline Religious affiliation & $0-1$ & $59.2 \%$ & & $60.8 \%$ & & $50.0 \%$ & & 0.000 & 0.000 & n.s. \\
\hline Visits to religious meetings & $1-5$ & 1.570 & 1.986 & 1.445 & 1.866 & 1.300 & 1.930 & 0.004 & n.s. & n.s. \\
\hline Frequency of meeting friends & $1-5$ & 4.969 & 0.267 & 4.986 & 0.163 & 4.970 & 0.288 & n.s. & n.s. & n.s. \\
\hline Alcoholic drinks weekend & $0-80$ & 6.188 & 8.559 & 5.281 & 8.321 & 4.049 & 7.042 & 0.000 & 0.000 & 0.054 \\
\hline Frequency of visiting the pub & $1-5$ & 2.849 & 1.682 & 2.632 & 1.661 & 2.461 & 1.645 & 0.000 & 0.023 & 0.026 \\
\hline Drugs ever taken & $0-6$ & 0.239 & 0.641 & 0.231 & 0.609 & 0.253 & 0.687 & n.s. & n.s. & n.s. \\
\hline Played truant past two months & $0-1$ & $16.7 \%$ & & $14.0 \%$ & & $16.3 \%$ & & n.s. & n.s. & n.s. \\
\hline Gender $($ male $=1)$ & $0-1$ & $51.6 \%$ & & $50.9 \%$ & & $51.4 \%$ & & n.s. & n.s. & n.s. \\
\hline Age in years & $13-18$ & 15.562 & 1.688 & 15.334 & 1.706 & 15.392 & 1.700 & n.s. & n.s. & 0.022 \\
\hline Ethnic minority & $0-1$ & $1.0 \%$ & & $2.8 \%$ & & $9.4 \%$ & & 0.000 & 0.000 & 0.010 \\
\hline Educational level & $1-4$ & 2.362 & 0.684 & 2.316 & 0.707 & 2.323 & 0.727 & n.s. & n.s. & n.s. \\
\hline Divorced parents & $0-1$ & $9.0 \%$ & & $8.7 \%$ & & $15.3 \%$ & & 0.000 & 0.000 & n.s. \\
\hline Minimum N & & & & & & & 111 & & & \\
\hline
\end{tabular}

All differences $p>0.05$ indicated n.s. To determine significance of differences, we used one sided chi-square tests for all dichotomous variables and Bonferroni post hoc tests for all ordinal and interval variables

delinquent behavior as compared to adolescents living in the rest of the country, whereas adolescents in non-urbanized areas do not differ from them. Note that standard deviations exceed mean scores, indicating that variation within the rural categories and within the rest of the country category is large.

We now turn to the indicators of communal social control. Both categories of rural adolescents participate in activities of associations and clubs more often as compared to all others. Both categories of rural adolescents also more often indicate that they belong to a religion. Adolescents living in non-urbanized areas go to religious meetings more often, as compared to their counterparts living elsewhere in the country, while the difference between adolescents living in sparsely urbanization areas and those living in the rest of the country is not significant in this respect.

With regard to peers and deviant behavior, there are no significant differences concerning the frequency of meeting friends. The number of alcoholic consumptions in the weekend (note that standard deviations exceed the mean scores) and the frequency of visiting pubs are clearly higher among the two categories of rural adolescents. Pub visiting is also higher among non-urbanized adolescents than among adolescents living in sparsely urbanized areas. Drug consumption and truancy do not differ significantly between the three categories of adolescents.

As for the socio-demographic control variables, the sample shows an equal gender distribution across the categories. Furthermore, adolescents living in non-urbanized areas are slightly older than their counterparts living in sparsely urbanized areas. This result is probably due to sampling bias. Also, the sample probably underestimates the proportion of ethnic minorities overall. However, for our purpose, the distribution of ethnic minorities across areas is more relevant. At this point, the sample does resemble the population: only very few of the rural adolescents are of ethnic minority descent, whereas the proportion of youngsters of non-Dutch ethnic descent is clearly higher in the rest of the country. Concerning educational level, no significant differences appeared between the three categories. Finally, the rates of parental divorce are significantly lower among the two categories of rural adolescents as compared to adolescents living in the rest of the country.

We conclude that the delinquency rates of adolescents living in sparsely urbanized areas are significantly lower than those of non-rural adolescents, while adolescents living in non-urbanized areas do not differ from their nonrural counterparts in this respect. Behind these delinquency rates different factors may play a role in delinquent behavior. Some indicators thought to reduce the chance of delinquent behavior score higher among both categories of rural adolescents (participating in activities of clubs or associations, religious affiliation, lower rate of parental divorce). On the other hand, some other factors that are known to increase the likelihood of delinquent behavior are higher among both categories of rural youngsters (drinking alcohol). In the following section, we will assess the impact of these factors in multivariate analyses. 


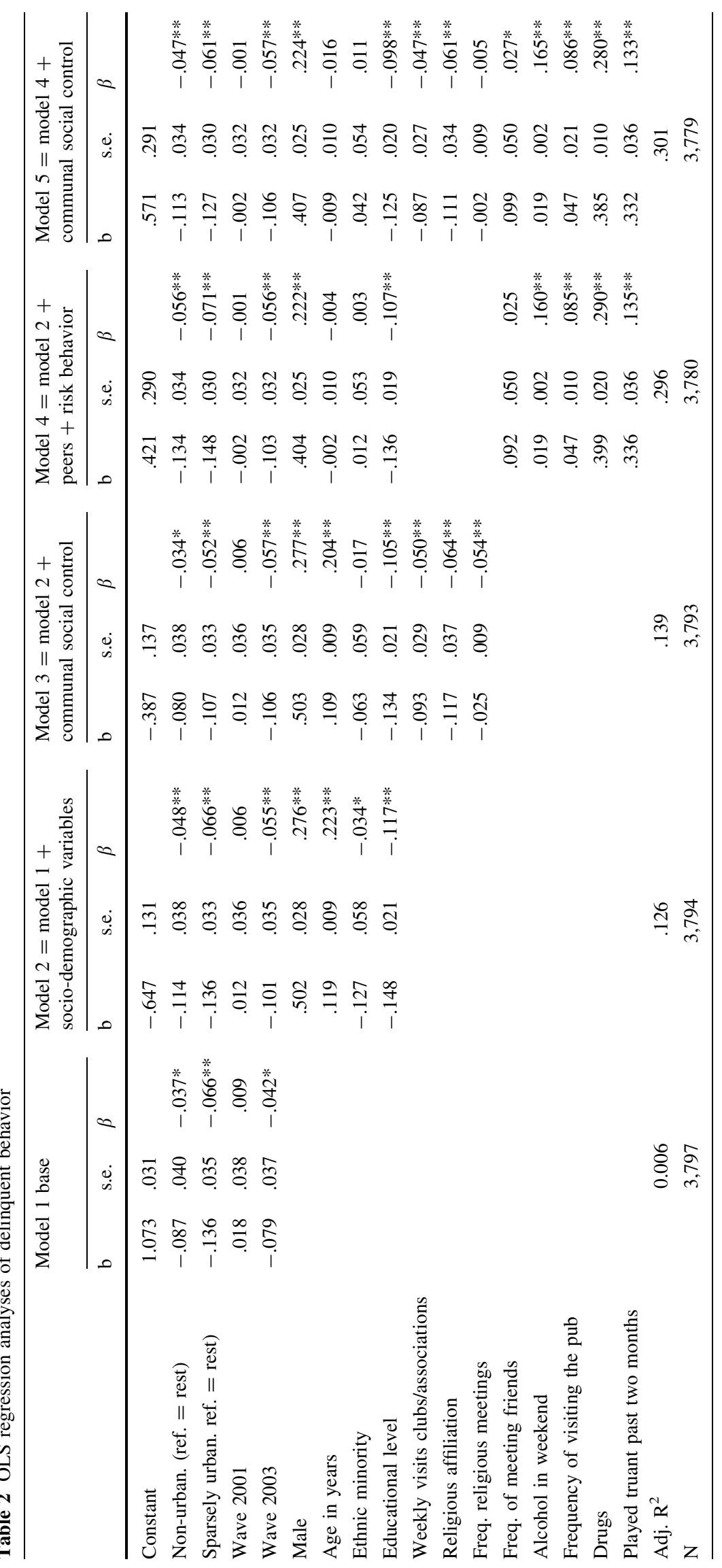




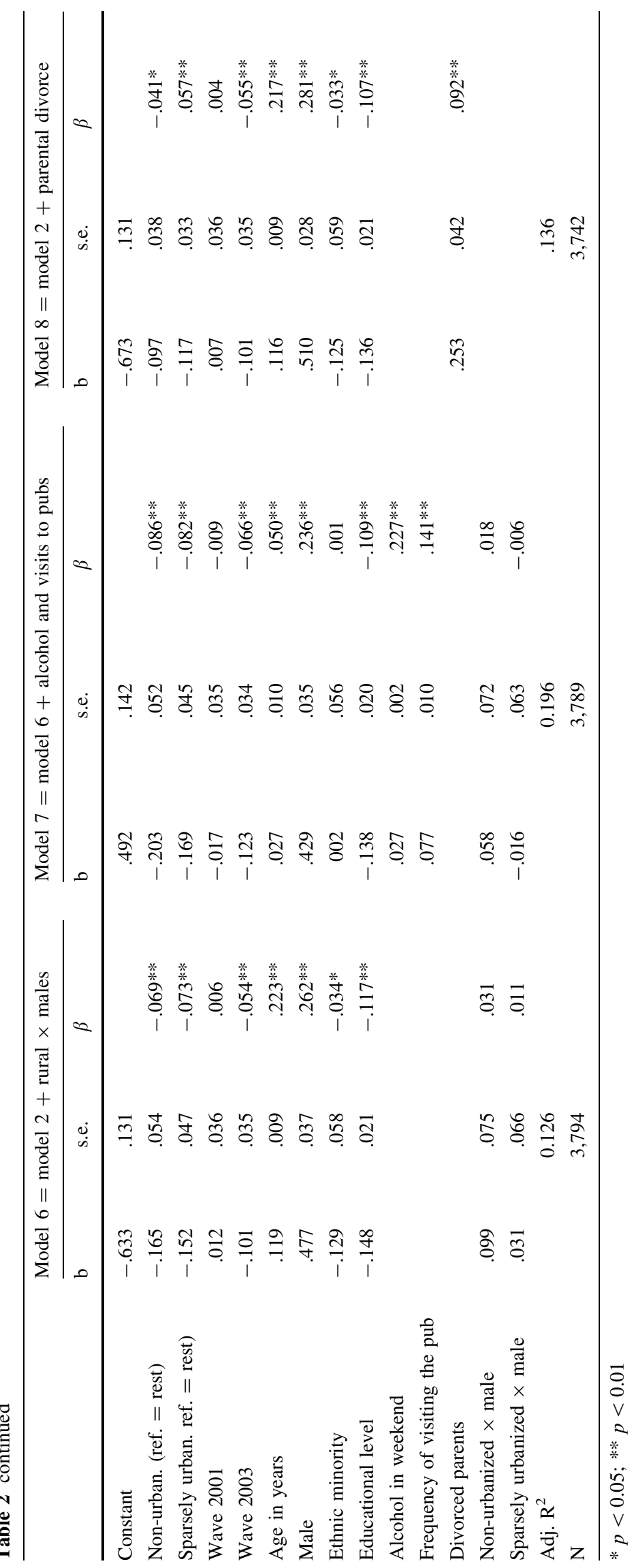


Table 3 Beta's of alternative or additional urbanization measures in OLS regression analyses of delinquent behavior

\begin{tabular}{lllllllll}
\hline & Model 1 & Model 2 & Model 3 & Model 4 & Model 5 & Model 6 & Model 7 & Model 8 \\
\hline$\beta$ 's 'big city' dummy variable & -.002 & .018 & .013 & .013 & .009 & .017 & .019 & .005 \\
Adj. R & .005 & .126 & .139 & .296 & .301 & .126 & .196 & .136 \\
$\beta$ 's ordinal urbanization measure & $.055^{* *}$ & $.070^{* *}$ & $.052^{* *}$ & $.079 * *$ & $.066^{* *}$ & $.082^{* *}$ & $.099^{* *}$ & $.057^{* *}$ \\
Adj. R & .005 & .126 & .139 & .296 & .301 & .127 & .197 & .136 \\
\hline
\end{tabular}

$* * p<0.01$

\section{Multivariate Statistics}

We now set out to test the hypotheses. Table 2 shows the results of linear regression analyses of adolescents' delinquent behavior (in these analyses, we transformed the delinquent behavior scale by taking its square root). The first model compares adolescents living in non-urbanized and sparsely urbanized areas with their counterparts living in the rest of the country (the reference category), only controlling for the year of data collection. It turns out that both rural categories engage in slightly less frequent delinquent behavior than adolescents living in the rest of the country.

In model 2, socio-demographic controls are added. In line with standard criminological research on juvenile delinquency, we see that males clearly are more likely to commit delinquent acts and that age also increases the likelihood of delinquent behavior. Ethnic minorities report a lower likelihood of engaging in delinquent behavior. The latter finding is inconsistent with prior Dutch criminological research based on self-report data (Kruissink and Essers 2004), which shows a slight overrepresentation of ethnic minorities in various forms of delinquent behavior. At this point, the sample might be biased, as our measure of ethnicity is not fully accurate. Finally, we see a negative effect of educational level. This means that adolescents following higher educational streams are less likely to engage in delinquent behavior. Including these controls only marginally alters the effects of both rural categories. Thus, the main conclusion we draw from model 2 is that rural adolescents have just a little bit lower delinquency rates after controlling for socio-demographic variables. We will use model 2 and the effects of both categories of rural adolescents specifically, as the reference for the models to follow.

We now turn to model 3, which includes indicators of communal social control. The first finding is that religious affiliation, church attendance and weekly participation in activities of clubs or associations slightly decrease the likelihood of engaging in delinquent behavior. The second finding is that controlling for these indicators of communal social control only marginally reduces the effects of both categories of rural adolescents, as compared to model 2 .
The latter finding rejects hypothesis 1: rural adolescents' greater exposure to communal social control does not reduce their likelihood of committing delinquent acts substantially.

Model 4 includes the frequency of meeting friends, alcohol and drugs consumption, the frequency of visiting pubs and playing truant. Except for the frequency of meeting friends, these indicators significantly influence the likelihood of engaging in delinquent behavior and also considerably increase the overall explanatory power of the model. We observe that controlling for these variables only slightly affects the effects of both categories of rural adolescents as compared to model 2 . This is due to controlling for their larger alcohol intake and, to a lesser extent, their greater frequency of visiting pubs. If we include only alcohol intake and visits to the pub in this model, the beta's increase and are significant: -.073 , and -.086 for adolescents living in non-urbanized and sparsely urbanized areas respectively. This means that drinking alcohol and visits to the pubs are associated with rural adolescents' delinquent behavior in particular.

Model 5 includes variables of communal social control to test hypothesis 2 stating that the association between rural adolescents' risk behavior and their delinquent behavior is substantially mitigated by greater exposure to communal social control. However, the effects of both categories of rural adolescents are reduced only marginally, revealing that rural adolescents' exposure to communal social control does not decrease substantially the association between their risk behavior and their engagement in delinquent activities.

Model 6 includes two interaction terms that differentiate males according to their place of living in order to test hypothesis 3 that claims that the difference in delinquency rates between rural and non-rural girls is larger than that between rural and non-rural boys. The interaction terms do not yield significant results and the effects of the main terms of both rural categories increased slightly. This means that, in accordance with hypothesis 3 , rural boys are on a par with boys living in the rest of the country while rural girls, indicated by the increased main effects of both rural categories, are less likely to engage in delinquent behavior than girls living in the rest of the country. Note 
also that the gender gap among rural adolescents is slightly larger among adolescents living in non-urbanized areas, as the change of this effect is of greater magnitude than that of adolescents living in sparsely urbanized areas.

In model 7, we include the consumption of alcohol during weekends and the frequency of visiting pubs in order to test hypothesis 4, which claims that drinking alcohol and visits to pubs have a stronger effect on young rural males' delinquent behavior as compared to young males living elsewhere. If this hypothesis is valid, we expect that including drinking alcohol and the frequency of visits to the pub decreases the effect of the interaction terms Non-urbanized $\times$ Males and Sparsely urbanized $\times$ Males. Indeed, we observe that the effects of both interaction terms have decreased, although it should be noted that the reduction is of small magnitude. We thus find support, albeit modest, for hypothesis 4 . Moreover, the negative effect of the two main terms (non-urbanized and sparsely urbanized areas) also increased, meaning that alcohol intake and visits to the pub also affect female rural adolescents more strongly than female adolescents living in the rest of the country. And this association is slightly stronger for rural female adolescents living in non-urbanized areas than for their counterparts living in sparsely urbanized areas. As we already observed, drinking alcohol and visiting pubs are correlates of delinquent behavior for both rural girls and rural boys in particular.

Finally, we included parental divorce in model 8 to test hypothesis 5 . This hypothesis claims that the lower rate of parental divorce substantially reduces rural adolescents' likelihood of committing delinquent acts. Here we observe that parental divorce yields a significant effect on the likelihood of engaging in delinquent behavior. Unlike hypothesis 5 , however, this results only in very small changes in the effects of both categories of rural adolescents.

We can infer the following from these analyses. First, we found somewhat lower delinquency rates among both categories of rural adolescents, after controlling for sociodemographic variables. Second, this difference cannot be accounted for by the greater exposure to communal social control that rural adolescents experience, as communal social control only very marginally inhibits delinquent behavior. Third, the greater numbers of alcoholic drinks in the weekend and the greater frequency of visiting pubs are a correlate of delinquent behavior for both rural girls and rural boys in particular, and this is even more the case for adolescents living in non-urbanized areas. Fourth, communal social control only marginally reduces the association between delinquent and risk behavior among rural adolescents. Fifth, the likelihood of engaging in delinquent behavior does not differ between rural and non-rural boys, whereas rural girls commit delinquent acts less often than non-rural girls. This also means that the somewhat lower delinquency rates of rural adolescents are largely the result of rural girls' lower likelihood of engaging in such behavior. The gender gap in delinquent behavior among rural adolescents is slightly larger in the non-urbanized areas than in the sparsely urbanized areas. Sixth, even though divorce rates are lower among the parents of rural adolescents, this only very slightly reduces delinquent behavior among rural youth.

Before we move to the discussion, we first show the results of additional analyses in which we used different indicators to measure degrees of urbanization. We ran the same models as presented in Table 2 twice. In the first round we added a "big city" dummy variable to the two rural categories. The additional dummy variable concerns the very strongly urbanized areas containing the larger part of what the Dutch consider "big cities" of over 400,000 inhabitants (Amsterdam, Rotterdam, The Hague and, to a lesser extent, Utrecht and some parts of smaller cities). The reference category now consists of intermediate categories of urbanization: moderately and strongly urbanized areas (see the section on method above). In the second round, we replaced the dummy variables with the five-item ordinal scale of urbanization. Table 3 gives the beta coefficients of the "big city" dummy variable and the five-item ordinal urbanization measure. The effects of all other indicators were very similar to the ones displayed in Table 2 .

Adding the "big city" dummy variable to the other two rural category dummy variables neither improves model fit, nor yields any significant effects. This means that adolescents living in these most strongly urbanized areas do not differ from adolescents living in the rest of the country. Replacing the two rural dummy variables with the ordinal urbanization measure yields a small significant positive effect in all models. As we just saw that adolescents living in the most strongly urbanized areas do not differ from those living in the rest of the country, the positive effect of the ordinal urbanization measure is not so much displaying a linear association between delinquent behavior and population density, but shows the existence of a threshold between rural and non-rural areas. To put it differently: Dutch rural adolescents are somewhat less likely to engage in delinquent behavior, not just compared to their counterparts living in big cities but also vis-à-vis adolescents living in all non-rural areas.

\section{Discussion}

Contrary to their counterparts in urban areas, rural adolescents have not been the focus of much criminological attention (but see Chilenski and Greenberg 2009; Osgood and Chambers 2000; Spano and Nagy 2005). This 
imbalance might be due to the ideology of the idyllic rural, which portrays social life in the countryside as pleasant and trouble free (Van Dam et al. 2002; Frank 2003; Short 2006), with close knit communities watching over the wellbeing of youth (Valentine 1997). The existence of delinquent rural adolescents does not fit in this romantic picture. However, this research shows that bad things do happen in the Dutch countryside: rural adolescents are only slightly less likely to engage in delinquent behavior than their counterparts living in big cities and in the rest of the country. Prior research focusing on youth antisocial behavior and (youth) violence also reports that the effects of population density are of rather small magnitude and that the inclusion of population density does not add much explanatory power (Barnett and Mencken 2002; Bouffard and Muftic 2006 but they found more pronounced ruralurban differences; Hagan and Foster 2001; Harden et al. 2009; Reijneveld et al. 2010). Osgood and Chambers (2000) found that only for small population sizes of 4,000 or less, youth violence rates rise with increasing juvenile population. Similar to the threshold effect we found, their analyses showed that beyond that level, increasing population density has little effect on arrest rates for most forms of youth violence.

Two theoretical approaches predict differences between rural and urban adolescents' delinquency rates. Social disorganization theory (Bursik 1988; Sampson 2009) predicts substantially lower delinquency rates of rural adolescents because of the greater degrees of informal social control in rural areas (Beggs et al. 1996; Simon et al. 2007; Vermeij and Mollenhorst 2008). This association may be direct or indirect. In the latter case, informal social control reduces adolescents' risk behavior (e.g. use of stimulants) which is known to be associated with delinquency. Cultural approaches on the other hand emphasize the more traditional value orientations and gender roles of rural adolescents and their parents (Adolfsen et al. 2006; Bock 2004; Little 2006) or they highlight the role of drinking alcohol as part of traditional performances of rural masculinity (Bye 2009; Campbell 2000). In the former reasoning, the gender gap in delinquency should be larger among rural than among urban adolescents and, given the association between parental divorce and delinquency (Agnew and White 1992; Hay 2003), overall delinquency rates of rural adolescents should be lower as their parents are less likely to divorce (Steenbekkers et al. 2006). In the latter reasoning, it is claimed that the association between drinking and delinquency is particularly strong for rural boys.

Unlike what social disorganization theory suggests, our indicators of communal social control (religious affiliation and frequency of visits to churches and clubs or associations) did not yield substantial effects. Even though rural adolescents are more often exposed to communal social control, this does not inhibit their delinquency rates so much. Also, communal social control does not affect the association between rural adolescents' delinquency and risk behavior substantially. Furthermore, whereas social disorganization theory regards the presence of single mothers as an indicator of reduced opportunities for parental supervision, we found that the lower rates of parental divorce in rural areas did not affect these adolescents' delinquency rates substantially. However, we should not dismiss social disorganization altogether on these grounds as we have been able to analyze just one of the mechanisms it proposes-albeit one considered of central importance. Prior studies which applied social disorganization theory to rural areas have provided support for the other mechanisms that the theory puts forward, notably the relationships between violent crime rates and rising levels of unemployment and residential instability (Barnett and Mencken 2002; Bouffard and Muftic 2006; Osgood and Chambers 2000).

We did find effects of the cultural indicators, however. To start with, we observed that the gender gap in delinquency is larger among rural adolescents. What is more, it is rural girls' lower likelihood of committing delinquent acts that accounts for the somewhat lower delinquency rates among rural adolescents overall, as rural boys did not differ from non-rural boys in this respect. The analyses also pointed out that drinking alcohol and visiting pubs are a correlate of delinquent behavior of rural adolescents-both girls and boys-in particular (see also Chilenski and Greenberg 2009). Interestingly, both the association between drinking and delinquency as well as the magnitude of the gender gap in delinquency are somewhat larger in the least densely populated of the two rural areas we analyzed.

Before we discuss how our findings contribute to the study of rural adolescence, we now indicate two limitations of this research. One shortcoming is that we had to rely on rather crude indicators of communal social control, so that the near absence of delinquency reducing effects of these indicators partly might be due to inaccurate measurements. However, even with these crude measures, we did find marked differences between rural and non-rural adolescents, which is in line with prior Dutch comparative ruralurban research (Steenbekkers et al. 2006; Vermeij and Mollenhorst 2008). We recommend that future studies also take other sources of informal social control into account. More specifically, the role of school managers in rural communities deserves attention as they play a central role in increasing these communities' involvement with local youth. Pro-active school managers not only reduce antisocial and delinquent behavior at school but also reach out to parents to involve them in exerting social control (Chilenski and Greenberg 2009; Spano and Nagy 2005). 
Another shortcoming is our inability to account for rural diversity; our measure of urbanization hides the variety of rural places from view within a certain category of population density (Cloke 2006; Halfacree 1993; Murdoch et al. 2003). Take, for example, the economic development of rural areas: whereas one area may suffer from long-term unemployment and deprivation, the other may benefit from tourism and second homes thanks to its attractive scenic beauty (see Lee et al. 2003 on the relationship between rural communities' economic development and violence). Furthermore, some studies point to the effects of the proximity or adjacency of a large city on rural communities' youth violence and crime rates, but the results are not unambiguous (Bouffard and Muftic 2006; Osgood and Chambers 2000). The large standard deviations of delinquent behavior within our two rural categories suggest that these and other intra-rural differences may influence rural adolescents' likelihood to engage in delinquent behavior. Such intra-rural differences were also found in a study of Pennsylvanian and Iowan communities, which showed that some rural communities had higher rates of both early adolescent stimulants use and juvenile delinquency than the national average (Chilenski and Greenberg 2009). Likewise, a study of adolescents in Alabama found that one rural county had more than double the state's average crime rate (Spano and Nagy 2005). Thus, we recommend that future studies try to account for the diversity of rural areas by generating data at lower levels of aggregation, for example at community or neighborhood level, and by including complementary measures of rurality rather than using indicators of population density only.

Despite these limitations, we think this research contributes to the study of adolescence in the following ways. Until now, the available research into the delinquent behavior of rural adolescents is based on US data. This research on Dutch adolescents is one of the few European contributions in the field. Given one of our main findingsrural adolescents' delinquency rates do not differ substantially from their urban counterparts-European students of adolescence have now even more reason to question the rural idyll. Another contribution of this study is that it shows that rural adolescents' delinquent behavior is linked to particular features of rural youth subculture rather than to the forms of communal social control we analyzed here. As we have seen, drinking alcohol and visiting pubs are the typical rural forms of adolescent risk behavior. Finally, this research shows that the rural adolescents' delinquent behavior is more gender specific as compared to that of other adolescents. Paradoxically, the deviant behavior of rural adolescents thus displays their conformity to more widely accepted traditional rural value orientations. We propose that future studies of rural adolescents explore the relationships between rural value orientations, the particularities of rural youth subcultures and delinquency further, while taking the variety of rural places and social networks into account.

Acknowledgments The author would like to thank the anonymous reviewers and Roger Levesque for their very valuable comments that have helped to improve this article.

Open Access This article is distributed under the terms of the Creative Commons Attribution Noncommercial License which permits any noncommercial use, distribution, and reproduction in any medium, provided the original author(s) and source are credited.

\section{References}

Adolfsen, A., Simon, C., \& Pierik, C. (2006). Emancipatie op het platteland. In W. Portegijs, B. Hermans, \& V. Lalta (Eds.), Emancipatiemonitor 2006 (pp. 262-285). Den Haag: Sociaal Cultureel Planbureau/Centraal Bureau voor de Statistiek.

Agnew, R. (1991). The interactive effects of peer variables on delinquency. Criminology, 29(1), 47-72. doi:10.1111/j.17459125.1991.tb01058.x.

Agnew, R., \& White, H. R. (1992). An empirical test of general strain theory. Criminology, 30(4), 475-500. doi:10.1111/j.1745-9125. 1992.tb01113.x.

Aseltine, R. (1995). A reconsideration of parental and peer influences on adolescent deviance. Journal of Health and Social Behavior, 36, 103-121. doi:10.1177/0011128707301627.

Bao, W.-N., Haas, A., \& Pi, Y. (2004). Life strain, negative emotions, and delinquency: An empirical test of general strain theory in the People's Republic of China. International Journal of Offender Therapy and Comparative Criminology, 48(3), 281-297.

Barnett, C., \& Mencken, F. C. (2002). Social disorganization theory and the contextual nature of crime in nonmetropolitan counties. Rural Sociology, 67(3), 372-393. doi:10.1111/j.1549-0831.2002. tb00109.x.

Beggs, J. J., Haines, V. A., \& Hurlbert, J. S. (1996). Revisiting the rural-urban contrast. Personal networks in nonmetropolitan and metropolitan settings. Rural Sociology, 61(2), 306-325.

Bock, B. (2004). It still matters where you live. Rural women's employment throughout Europe. In H. Buller \& K. Hoggart (Eds.), Women in the European countryside (pp. 14-41). Aldershot: Ashgate.

Bouffard, L. A., \& Muftic, L. R. (2006). The "rural mystique": Social disorganisation and violence beyond urban communities. Western Criminology Review, 7(3), 56-66. http://wcr.sonoma. edu/v07n3/wcr073.oct2006.pdf\#page $=62$.

Bursik, R. J. (1988). Social disorganization and theories of crime and delinquency: Problems and prospects. Criminology, 26(4), 519-552. doi:10.1111/j.1745-9125.1988.tb00854.x.

Bye, L. M. (2009). How to be a rural man. Journal of Rural Studies, $25,278-288$.

Campbell, H. (2000). The glass phallus: Pub(lic) masculinity and drinking in rural New Zealand. Rural Sociology, 65(4), 562-581. doi:10.1111/j.1549-0831.2000.tb00044.x.

Carrington, K., \& Scott, J. (2008). Masculinity, rurality and violence. British Journal of Criminology, 48(5), 641-666. doi:10.1093/ bjc/azn031.

Chilenski, S. M., \& Greenberg, M. T. (2009). The importance of community context in the epidemiology of early adolescent substance use and delinquency in a rural sample. American Journal of Community Psychology, 44(3), 287-301. 
Cloke, P. (2006). Conceptualizing rurality. In P. Cloke, T. Marsden, \& P. H. Mooney (Eds.), The handbook of rural studies (pp. 18-28). London: Sage.

Den Dulk, C. J., Van de Stadt, H., \& Vliegen, J. M. (1992). Een nieuwe maatstaf voor stedelijkheid: de omgevingsadressendichtheid. Maandstatistiek bevolking, 7, 14-27.

Devilee, J., \& De Hart, J. (2006). Maatschappelijke participatie. In A. Steenbekkers, C. Simon, \& V. Veldheer (Eds.), Thuis op het platteland. De leefsituatie van platteland en stad vergeleken. Den Haag: Sociaal en Cultureel Planbureau.

Emmelkamp, R. (2004). Opgroeiende jongeren en veiligheid in stad en land: de zorgen van ouders ontrafeld. $B \& M, 31(3), 185-193$.

Frank, R. (2003). When bad things happen in good places: Pastoralism in big-city newspaper coverage of small-town violence. Rural Sociology, 68(2), 207-230. doi:10.1111/j.1549-0831. 2003.tb00135.x.

Hagan, J., \& Foster, H. (2001). Youth violence and the end of adolescence. American Sociological Review, 66(6), 874-899. http://www.jstor.org/stable/3088877.

Halfacree, K. (1993). Locality and social representation: Space, discourse and alternative definitions of the rural. Journal of Rural Studies, 9(1), 23-37. doi:10.1016/0743-0167(93)90003-3.

Harden, K. P., D'Onofrio, B. M., Hulle, C. V., Turkheimer, E., Rodgers, J. L., Waldman, I. D., et al. (2009). Population density and youth antisocial behavior. Journal of Child Psychology and Psychiatry, 50(8), 999-1008. doi:10.1111/j.1469-7610.2009. 02044.x.

Hay, C. (2003). Family strain, gender and delinquency. Sociological Perspectives, 46(1), 107-135. doi:10.1525/sop.2003.46.1.107.

Haynie, D. L., \& Osgood, D. W. (2005). Reconsidering peers and delinquency: How do peers matter? Social Forces, 84(2), 1109-1130. doi:10.1353/sof.2006.0018.

Hirschi, T. (1969). Causes of delinquency. Berkeley: University of California Press.

Koning, I. M., Engels, R., Verdurmen, J. E. E., \& Vollebergh, W. A. M. (2010). Alcohol-specific socialization practices and alcohol use in Dutch early adolescents. Journal of Adolescence, 33(1), 93-100.

Kruissink, M., \& Essers, A. A. M. (2004). Zelfgerapporteerde jeugdcriminaliteit in de periode 1990-2001. Den Haag: WODC.

Laub, J. H. (1983). Patterns of offending in urban and rural areas. Journal of Criminal Justice, 11(2), 129-142. doi:10.1016/ 0047-2352(83)90048-X.

Lee, M. R., Maume, M. O., \& Ousey, G. C. (2003). Social isolation and lethal violence across the metro/nonmetro divide: The effects of socioeconomic disadvantage and poverty concentration on homicide. Rural Sociology, 68(1), 107-131. doi:10.1177/ 1088767905283640

Little, J. (2006). Gender and sexuality in rural communities. In P. Cloke, T. Marsden, \& P. H. Mooney (Eds.), The handbook of rural studies (pp. 365-378). London: Sage.

Loeber, R., Pardini, D., Homish, D. L., Wei, E. H., Farrington, D. P., Creemers, J., et al. (2005). The prediction of violence and homicide in young men. Journal of Consulting and Clinical Psychology, 73(6), 1074-1088.

Mahoney, J. L. (2000). School extracurricular activity participation as a moderator in the development of antisocial patterns. Child Development, 71(2), 502-516. doi:10.1111/1467-8624.00160.

Mahoney, J. L., \& Stattin, H. (2000). Leisure activities and adolescent antisocial behavior: The role of structure and social context. Journal of Adolescence, 23(2), 113-127. doi:10.1006/jado.2000. 0302.

Matsueda, R. L., \& Anderson, K. (1998). The dynamics of delinquent peers and delinquent behavior. Criminology, 36(2), 269-308. http://faculty.washington.edu/matsueda/Papers/Dynamics $\% 20$ of $\%$ 20Peers.pdf.
Mulder, J. (2005). Indrinken op eigen erf: landelijk veldonderzoek naar jongerenontmoetingsplekken in een semiparticuliere omgeving. Utrecht: Stichting Alcohol Preventie.

Murdoch, J., Lowe, P., Ward, N., \& Marsden, T. (2003). The differentiated countryside. London: Routledge.

Osgood, D. W., \& Chambers, J. M. (2000). Social disorganization outside the metropolis: An analysis of rural youth violence. Criminology, 38, 81-115.

Poelen, E. A. P., Scholte, R. H. J., Engels, R. C. M. E., Boomsma, D. I., \& Willemsen, G. (2005). Prevalence and trends of alcohol use and misuse among adolescents and young adults in the netherlands from 1993 to 2000. Drug and Alcohol Dependence, 79(3), 413-421.

Raistrick, D., Hodgson, R., \& Ritson, B. (Eds.). (1999). Tackling alcohol altogether. London: Free Association Books.

Reijneveld, S. A., Veenstra, R., de Winter, A. F., Verhulst, F. C., Ormel, J., \& de Meer, G. (2010). Area deprivation affects behavioral problems of young adolescents in mixed urban and rural areas: The TRAILS study. Journal of Adolescent Health, 46(2), 189-196. http://irs.ub.rug.nl/dbi/4beac078a7066.

Sampson, R. J. (2009). Disparity and diversity in the contemporary city: Social (dis)order revisited. British Journal of Sociology, $60(1), 1-31$.

Sampson, R. J., \& Groves, W. B. (1989). Community structure and crime: Testing social-disorganization theory. American Journal of Sociology, 94(4), 774-802. http://wjh1.wjh.harvard.edu/soc/ faculty/sampson/articles/1989_AJS_Groves.pdf.

Sampson, R. J., \& Laub, J. (1992). Crime and deviance in the life course. Annual Review of Sociology, 18(1), 63-84. http:// coglab.wjh.harvard.edu/soc/faculty/sampson/articles/1990_ASR_ Laub.pdf.

Sampson, R. J., \& Raudenbush, S. W. (1999). Systematic social observation of public spaces: A new look at disorder in urban neighborhoods. The American Journal of Sociology, 105(3), 303-651. http://links.jstor.org/sici?sici=0002-9602\%28199911\% $29105 \% 3 \mathrm{~A} 3 \% 3 \mathrm{C} 603 \% 3 \mathrm{ASSOOPS} \% 3 \mathrm{E} 2.0 . \mathrm{CO} \% 3 \mathrm{~B} 2-\mathrm{G}$.

Shaw, C. R., \& McKay, H. D. (1942). Juvenile delinquency in urban areas. Chicago: University of Chicago Press.

Short, B. (2006). Idyllic ruralities. In P. Cloke, T. Marsden, \& P. H. Mooney (Eds.), The handbook of rural studies (pp. 133-148). London: Sage.

Simon, C., Vermeij, L., \& Steenbekkers, A. (2007). Het beste van twee werelden. Plattelanders over hun leven op het platteland. Den Haag: Sociaal en Cultureel Planbureau.

Spano, R., \& Nagy, S. (2005). Social guardianship and social isolation: An application and extension of lifestyle/routine activities theory to rural adolescents. Rural Sociology, 70(3), 414-437.

Steenbekkers, A., Simon, C., \& Veldheer, V. (Eds.). (2006). Thuis op het platteland. De leefsituatie van platteland en stad vergeleken. Den Haag: Sociaal en Cultureel Planbureau.

Sutherland, E. H., Cressey, D. R., \& Luckenbill, D. F. (1992). Criminology (11th ed.). Dix Hills, NY: General Hall.

Tomsen, S. (1997). A top night: Social protest, masculinity and the culture of drinking violence. British Journal of Criminology, 37(1), 90-102.

Valentine, G. (1997). A safe place to grow up? Parenting, perceptions of children's safety and the rural idyll. Journal of Rural Studies, 13(2), 137-148. http://www.sciencedirect.com/ science/article/B6VD9-3SWY7WR-1/2/5fcc7edda1edc938697a 968 a352bac46.

Van Dam, F., Heins, S., \& Elbersen, S. B. (2002). Lay discourses of the rural and stated and revealed preferences for rural living. Some evidence of the existence of a rural idyll in the Netherlands. Journal of Rural Studies, 18(4), 461-476. doi:10.1016/S07 43-0167(02)00035-9. 
Van de Rakt, M., Weerman, F., \& Need, A. (2005). Delinquent gedrag van jongens en meisjes Het (anti)sociale kapitaal van vriendschapsrelaties. Mens \& Maatschappij, 80(4), 328-352.

Vermeij, L., \& Mollenhorst, G. (2008). Overgebleven dorpsleven. Sociaal kapitaal op het hedendaagse platteland. Den Haag: Sociaal en Cultureel Planbureau.

Weisheit, R. A., \& Donnermeier, J. F. (2000). Change and continuity in crime in rural America. In R. A. Weisheit \& J. F. Donnermeier (Eds.), The nature of crime: Continuity and change. Washington D.C.: US Dept. of Justice, Office of Justice Programs.
Sociology at the University of Amsterdam. His main research interests are juvenile street violence in rural and urban areas, and cultural analyses of social control and social cohesion in small villages. He is currently involved in a research project into juvenile violence in Dutch rural and urban areas, supported by the Netherlands' Organization for Scientific Research Veni-Grant no. 016.095.167.

\section{Author Biography}

Don Weenink is an Assistant Professor of Sociology at the Rural Sociology Group, Department of Social Sciences, Wageningen University, the Netherlands. Don Weenink received his Ph.D. in 